Vol. 11 (4), pp. 33-44, December 2016

DOI: $10.5897 /$ INGOJ2016.0317

Article Number: 728A49D62089

ISSN 1993-8225

Copyright (c) 2016

Author(s) retain the copyright of this article

http://www.academicjournlas.org/INGOJ

\title{
NGOs' performance in conservation governance: Cases of nature conservation campaigns in China
}

\author{
Zhao Li \\ R410, GoetheStr.66, 44147, Dortmund, Germany. \\ Received 2 December, 2016; Accepted 6 December, 2016
}

\begin{abstract}
After the phase of Command-Control Mechanism in the 1970s and Market-oriented Mechanism in the 1980s, the evolution of China's state governance has moved on to the third phase of Information disclosure, dialogue and cooperation mechanism. Accordingly, spatial governance is going through a similar process. The importance of public participation (PP) was addressed in China's Agenda 21. In 1996, PP mechanisms were established in spatial governance projects (State council, 1996), and then introduced into an Environmental Impact Assessment (EIA) legal mechanism (Standing Committee of the National People's Congress, 2002). Thereafter, PP has been gradually institutionalized and substantiated into spatial governance practice. Composed of citizens who share similar concerns or attitudes towards specific issues, an NGO is generally expected to be more positively influential than un-organized individual participants on decision-making and negotiation process. In natural conservation regions, conflicts between regional construction planning and environment protection are fierce. What role should the NGOs play in those regions, considering this dilemma? Could the current laws and regulations ensure all voices are being heard and taken into account? In China, NGO's participation in conservation governance practices remains passive and hard to achieve. Effectiveness of NGO's participation largely depends on publicity and mainstream public opinion on major media platforms. NGOs' participation helps supervise conservation governance practice, while NGO's participation itself needs to be better guaranteed by a controlled implementation of relevant regulations. Suggestions for improving NGOs performance includes to promote the legal regime of participatory conservation planning, and to establish sound cooperation between the mass media and the NGOs.
\end{abstract}

Key words: NGO; nature reserve; participation.

\section{INTRODUCTION}

\section{RESEARCH BACKGROUND}

The early $21^{\text {st }}$ century sees new shifts in China's environmental governance. The concepts of information disclosure and public participation for decision making were first advocated by China State Government in the late 1990s and then, as public awareness about governance issues raises, the mechanism of information disclosure, dialogue and cooperation is established step by step. In accordance, spatial governance involving

E-mail: lizhaola@gmail.com. Tel: +0049-17681571876.

Authors agree that this article remain permanently open access under the terms of the Creative Commons Attribution License 4.0 International License 
environmental issues is going through a similar process.

Confrontations between regional economic development and environment protection are all but new, in the practices of spatial planning and governance. Specifically, conflicts could be extremely fierce in nature conservation zones, where construction projects are (or expected to be) under rigid control, whereas local officials or foreign investors express strong will to exploit natural resources, driven by the subsequent economic interests. Cases exist, in which the range and boundary of nature reserve are adjusted, in order to legalize major construction projects. There are also reports claiming that major construction work in nature reserve starts without official approval from competent authorities in less developed regions of China.

Though it has been vigorously referred in Decision of the State Council on Several Issues Concerning Environmental Protection (State Council, 1996), that the mechanism of public participation should be established, and effect on environmental governance, it is unrealistic that every individual's voice heard by decision makers. In this case, Non-Governmental Organizations (NGO) act as the delegate of citizens, who hold similar viewpoints, gathering and conveying main stream public opinions to the government. Among the numerous environment protection campaigns in natural conservation regions, two of the NGO-propelled cases stand out, demonstrating that NGOs could practically affect the outcomes of decision making process.

What is the role of NGO in negotiating and resolving the conflicts between regional development and environment protection? How is their performance in practice? What are the constraints and opportunities of participatory conservation governance? This paper seeks answers to those questions through legislation interpretation and in-depth case study.

\section{Objectives}

The purposes of this paper are: (1) Analyze the effectiveness and efficiency of NGOs' participation in practices, and (2) Bring forward suggestions for participatory spatial governance. The beginning point of this paper is a prestigious campaign among NGOs in China, the cancelling of construction in one section of a provincial highway. In the original plan, this section of highway would have cut through the national wetland conservation zone of Liao River estuary, breeding ground for spotted seal (Phoca largha) and Chinese blackheaded gull (Larus saundersi). Through literature review and interview, this paper will not only objectively reproduce the 2011 campaign and negotiation process, but also outline the background and sequential influence of the NGOs campaign through 2015. The adoption of inductive method and comparison method contributes to rigorous conclusions, deduced from all case studies.

\section{Legislation regime for nature reserve governance and public participation}

Laws and regulations that have effect on spatial governance in natural conservation regions could be divided in two categories based on governance subjects, namely the governance of natural conservation region itself, and of construction projects with potential impact on the environment.

China's first natural conservation zone was established in 1956. The number of nature reserves has reached 926 by the year 1997. In contract to the rapid setting of conservation zones, legalization process for their governance was severely delayed. It was not until 1994 , that a set of comprehensive administrative regulations on nature reserves were set into effect and regarded as the legislation basis for nature reserve governance thereafter. Integrated management and separate departmental management were combined in the system of nature reserve governance (State Council, 1994). For instance, one single nature reserve could be governed by the local forestry department, agriculture department and a separate nature reserve department at the same time, causing confusion over the allocation of responsibilities among those various governing bodies. The local people's government which approved the establishment of nature reserve had the full right to define ranges and boundaries; change conservation type, ranges and boundaries; review regional plans, and cancel the nature reserve. Nature reserve administrative agency, the environment protection and land management administrative departments were in charge of making regional plan, and supervise all influential human activities within the range of nature reserve. However, the penalties for violation were considerably weak. Detailed enforced penalties for construction projects which violate the regulations would be issued and monitored by environment protection or land management administrative department of the local people's government above the county level (China Land Administration Bureau, 1995). This led to a loophole in conservation governance, when irregularities would gain approval from related local department, in the name of regional economic development.

Conservation governance for national nature reserve was promoted by the Provisions on the Administration of Adjustments to National Nature Reserves in 2002. Authority of defining and adjusting the boundaries was referred to the local people's government and the State Environment Protection Administration (SEPA), or Ministry of Environment Protection (MEP) after 2008. It was first elucidated in regulations that adjustment of the boundaries could be made, when it imposes constraints to "major national construction project". Major national 
construction project indicates the construction project approved by the State Council or the department authorized by the State Council (State Council, 2013).

Under this circumstance, an Environmental Impact Assessment (EIA) report of the construction project must be reviewed and approved by both the Committee of National Nature Reserve and SEPA (State Council, 2002; State Council, 2013). Local residents' opinion is specifically listed as a compulsory documentation material for project assessment (State Council, 2013). Once the adjustment is approved, result shall to be disclosed within three months, but feedback mechanism is not mentioned in effective regulations.

In conclusion, the spatial governance for nature reserves is conducted by the environment protection and nature reserve administrative departments of its corresponding governmental level. Despite of the increasing calls for participatory governance, the top-down mechanism still plays the dominant role in practice. The opportunity for legitimate public participation lies in EIA and the preparation phase for nature reserve adjustment application.

Unlike the conventional public opinion gathering mechanism, for instance Major's Mailbox, Government Hotline, etc., public participation mechanism in EIA is highly regulated in its timing of intervention and claims' topic. EIA is known as an effective instrument in environment protection. Subjects of EIA covers a spectrum of all spatial plan and governance concerning environmental issues. The concept of EIA was introduced by the Chinese government in the 1970s, but relative provisions remained scattered and vaguely formulated until the promulgation of Law of the People's Republic of China on Appraising of Environment Impacts (EIA Law) in 2002 (Beyer, 2006).

Similar to the legal regime establishment of EIA, legalization for its participation mechanism has gone through a slow process and is facing even more obstacles. The concept of public participation was specifically emphasized in a chapter in China's Agenda 21. Public participation was soon perceived as a tool for achieving sustainable development and environment protection. The Decision of the State Council on several issues concerning environmental protection (1996) provided a critical opportunity, so that public participation could be included in the country's legal regime. Effective provisions on public participation were first included in the EIA Law, an epoch-making event in the field of environment protection.

According to the EIA Law, an EIA shall be conducted, when planning or construction projects would impose unfavorable impact to the environment. The institution which provides technical service to drafting the EIA shall not have "any affiliation" with the planning or construction entity of the project, and have adequate qualification. Approval of the project would not be granted by the approval organ without the submission of EIA report.
Department designated by the people's government shall summon experts and representatives from relevant departments to form the approval committee. The start of construction without submitting relevant document and being granted with approval is conceived illegal; the people responsible for the project shall receive administrative punishment or criminal liabilities, appropriate to the nature of their acts.

In the EIA Law, 3 out of 38 articles mentioned participatory decision making. Planning or construction entities are in charge of organizing demonstration meetings, hearings or other forms of communication methods to seek public opinions about the EIA draft, before submitting the draft of project to the approval organ. Public opinions shall be included in the final EIA report, with the comments from planning or construction entities. Though the principles of public participation were introduced in the EIA Law, no operational instructions were addressed. As a consequence, the authenticity and impartiality of public opinions included in EIA report would be unreliable. For instance, in Shenzhen-Hong Kong west channel-Shenzhen Sideway Project, public survey was conducted by Shenzhen environmental science research center only to fulfill the requisitions in the EIA Law (Liu, 2005). Merely 50 residents in one residential area participated through questionnaire investigation, while approximately 200,000 residents who would also be affected by the project were not informed of any forms of public survey.

In order to remedy this defect, the SEPA promulgated the Temporary Act of Environmental Impact Assessment of Public Participation in 2006. It legitimized the public survey to be carried out by EIA institutions. Public survey result and construction entities' comments shall be written in a separate chapter in EIA report. Information about environmental impact shall be disclosed to the public through "well known" media, no later than 7 days after EIA institution is designated. The draft of EIA shall be "easily accessible" for at least 10 days, before being submitted for approval (SEPA, 2006). Relative information would be issued be the announcement from construction entities or EIA institutions. Alongside with the improvement of EIA framework, this temporary act also stipulate detailed instructions on how the public survey shall be organized, Environment protection departments are also responsible for reviewing the public survey chapter in EIA, to ensure the effectiveness of public survey.

Jet another deficiency remains overlooked. Information disclosure is perceived as the basis for active public engagement. Regrettably, though disclosure for environmental information was addressed in the temporary act of public participation in EIA, no provisions for project information disclosure have been issued. Public opinions are not collected until draft of the EIA is formulated. Generally by the time EIA draft is completed, the project would be started within a short time. Delay of 
construction work caused by protests would lead to heated conflicts between the protester and the project initiator. Considering the time point of intervention, the general public acts more as a critic and supervisor rather than a proactive participant in spatial governance.

\section{History and working mechanism of NGOs in China}

Individuals of the general public can freely voice their opinions, mainly complaints, to responsible departments. However, as it could be inferred from the legal environment, there is no easy way for an individual to challenge a draft project plan. On the other hand, NGOs convenes citizens who share similar concerns or attitudes towards specific issues. Through sound-structured working schedule, they are able to implement preemptive and lobbying activities, and as a result, expected to be more influential than un-organized individual participants on decision-making and negotiation process (Schwartz, 2004).

The Registration and Administration of Social Organizations (RRASO) promulgated in 1989 is the first and only legal documentation concerning NGO affairs in China (Knup, 1997). In the Chinese context, aside from the conventional NGOs which are sponsored and supported by non-government entities, there is a large group of NGOs with "Chinese characteristics", Government-Organized NGOs (GONGOs), as they are referred by western scholars. Ironically, the GONGOs are sponsored by state funding and have strong official affiliation with state agencies or institutions (Schwartz, 2004). They are conceived as the least autonomy NGOs as they implement a top-down operating model. In this case, this paper will not argue and explore the effectiveness of GONGOs, as they possess severely limited competence in expressing authentic public opinion.

Though considered as "relatively independent" organizations, registered NGOs are supervised by relevant government bureau, and shall renew their registration annually, according to the revised RRASO (1998). The attitude of the government is still fatally decisive to the future of NGOs. Nevertheless, NGOs are generally cooperative with the government. In the study conducted by Beijing NPI NPO Development Center (2010), over $70 \%$ of the 200 sampled environmental NGOs have received various forms of support from the government, and expect collaboration with the government in the future.

NGOs are engaged in a large spectrum of orientations. Among them, Environmental NGOs (ENGOs) have specific focus on spatial governance issues. There is a disputation about the first registered ENGO in China, Protection Association of Saunders's Gull (PASG) or Friends of Nature (FON), both will be referred to in the case study section of this paper. According to the statistics, approximately 320 ENGOs are active by the end of 2010. The majority of ENGOs focus only on local problems, while over $26 \%$ of ENGOs allocate in metropolitans such as Beijing and Shanghai. Imbalanced geographical distribution of ENGOs makes it more difficult to work in less developed regions. Speaking of the working focus of ENGOs, the leader of PASG, Detian Liu, claimed that diffusing knowledge about environment and species protection is the initial working targets for the majority of ENGOs. Scientific research is their secondary working focus. As it is acknowledged, environmental data are seldom publicly available in China, imposing grave constraints to ENGOs' research work. Fortunately, the deficiency of scientific knowledge could be remedied, thanks to the practical experiences of the local ENGOs. In the case of Black-neck Crane Protection Association (BCPA), the chairperson of the BCPA, a former photographer, organized volunteer trainings and scientific expenditures for over ten years, and published over thirty articles in scientific journals. Through knowledge popularization, BCPA also helped to relieve the tension between species protection and local agricultural development. Achievements of BCPA not only contribute to conservation biology, but also provide theoretical and practical support for the governance of the National Nature Reserve for Black-neck Crane where it works.

Traditionally, ENGOs in China promote public awareness via organizing lectures and conferences, as well as publishing research work or observation report to news media and scientific journals. With the continuing popularization of the Internet, online discussion becomes an easy and effective method for ENGOs to communicate with interested individuals. Meanwhile, the numbers of followers of different ENGOs distinguish dramatically. It is never an easy task for local and small-scale ENGOs to gain popularity in the mainstream social network, due to their limited competency in organizing influential activities.

Despite the fact, that over $84 \%$ of ENGOs would like to share information with other social organizations, only half of them conduct joint activities with one another regularly (NPI, 2010). Collaboration is more common among the few prestigious ENGOs than local ENGOs working in remote regions. The polarization of the ENGOs is hard to eliminate.

Few of the ENGOs show the willingness and capability to attempt legal and political action, concerning the risk of being rejected to register for the coming year. Considering the legal regimes, the most distinguishing participatory work of ENGOs in nature conservation regions is confined to evaluating EIA draft. Cases are rare, in which ENGOs stand out to make a difference. Is their participation effective? What are problems they encountered in practice? Questions will be answered in the case study section.

To conclude, though perceived to be more influential than individuals, conventional ENGO's possess undermined efficiency to convey independent thoughts in 
decision making process of spatial planning. Major constraints from nature of ENGOs lies in their own insufficiencies, but most formidable, the pressure of administrative regime for NGOs.

\section{CASE STUDY OF NGOS ROLE IN ENVIRONMENTAL GOVERNANCE}

\section{Route selection proposal for provincial highway project}

\section{Background}

Provisions on nature reserve were promulgated in the 1990s, by which time, massive natural resource exploitation and industrialization have already taken place in the vast territory of China. In the case of Liaohe National Nature Reserve (LNNR), environmentalists encounter a variety of contrary voices, due to the remaining problems from LNRR's troubled past, as well as new challenges from modernization.

LNNR locates on the wetland in Liaoning Province, stretching $80,000 \mathrm{hm}^{2}$ along the estuary of Liaohe River. It is of significant importance for protection, as a migration terminal for water fowls, and the only breeding ground for spotted seals (Phoca largha) in China. Local productivity developed rather slowly before the $20^{\text {th }}$ century. It was not until 1928, modernized agriculture was introduced into this region, accompanied with large scale construction work. Since the Japanese occupation in the late $1930 \mathrm{~s}$, reeds were massively harvested by human power to produce paper. Fishery and aquaculture also started during this period. In 1970, Liaohe oil field (the seventh largest oil field in China currently) was established and put into service thereafter. Approximately $10,000 \mathrm{hm}^{2}$ of the wetland was implanted with oil pumping devices and transportation routes. Biologists spotted red- crowned crane (Grus japonensis) in 1982, their discovery resulted in the founding of LNNR in 1988 . The $21^{\text {st }}$ century sees a sprouting of various Special Economic Zones. From the perspective of administrative segmentation, LNNR is within the jurisdiction of Panjin city and the newly founded Liaohekou Eco-economic zone in accordance with its geographical location. As a national nature reserve, three specific departments are responsible for its governance, Panjin Forestry Bureau, Panjin Liaohe Reserve Management Bureau, and Liaoning Liaohekou National Nature Reserve Management Bureau, respectively.

The brief introduction of the history elucidates the sophisticated develop-conserve dilemma in LNNR. Local stakeholders could be coarsely grouped as: The general residents, environmentalists, entrepreneurs and government officials. Results of the questionnaires and interviews conducted between 2012 and 2013 reveal their differentiated claims. Those surveys covered three permanent settlements located within the experimental zone of LNNR. Senior local residents are aware of environmental destruction, but the younger generation care more about the poverty and under-development problems in the region. Environmentalists generally have working relationship with NGOs or local nature reserve bureau. They advocate different develop strategies towards one specific issue, which will be depicted later. Entrepreneurs boast tight affiliation with the local government, environmental conflicts are either not reported to or overlooked by them. Local government officials are familiar with the actual situation, but in their perspective, the urgent call for regional development outweighs animal habitat conservation.

\section{NGOs' participatory actions in the project}

Unfortunately, the deep rooted attitudes of those stakeholder groups did not change much after the famous "2011 NGOs' Campaign" which took place exactly in LNNR. On January, $31^{\text {st }}, 2011$, the approval of the construction project Liaoning Provincial Seaside Highway: Tanghai-Sandaogou Section" went into publicity on the website of Liaoning Provincial Development and Reform Commission. Panjin City Government Website released an announcement, calling for public opinions for EIA from February $16^{\text {th }}$ to $26^{\text {th }}$. It was not until March $18^{\text {th }}$, that Jiguang Tian, chairman of Panjin City Association of Volunteers for the Protection of the Spotted Seals (PJSSA) first read the announcements and spotted road construction devices on site. In the original plan, an elevated bridge will be built right over the breeding ground of spotted seals.

Failed to contact with all directly related entities, including the design company, construction company and EIA institution, and did not receive response from Major's Mailbox, the chairman of PJSSA consulted to the Internet Media. With the help from over 15 ENGOs nationwide, the topic "Highway construction invading spotted seals' habitat" won a rapid media exposure. Tian's article on a social network, Sina Weibo alone, was retweeted for over 10,000 times within 10 days. Under the pressure of public opinion, Panjin City Government organized three colloquiums to further discuss about the site selection of an elevated bridge. All relevant institutions were invited, including Tian as the representative of NGO. It should be noted, that the time for EIA public opinion collection process has already passed.

According to Tian, other NGOs not only created propaganda, but also provided practical suggestions on how to effectively convey opinions to government officials and EIA exports. In the colloquium, Tian questioned about the qualification of EIA institution and proposed suggestions from NGOs. Two of Tian's drafts for the route selection were rejected, according to which the highway would intrude into the range of the experimental zone of LNNR (Figure 1). His other 


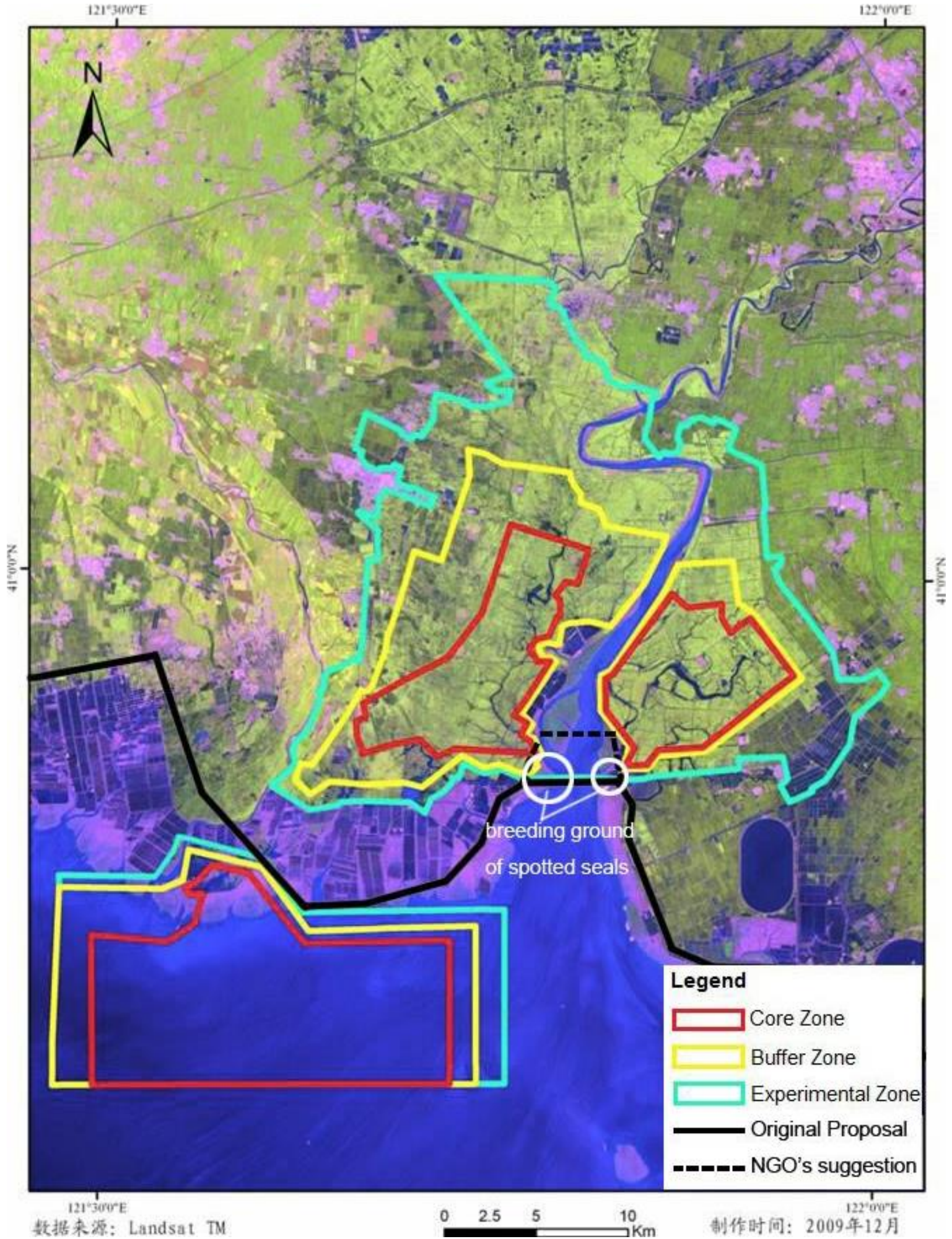

Figure 1. Zoning map of LNNR and route selection proposals. Geographical location of the breeding ground and road design provided by Tian, illustration translated and adapted by author.

suggestions addressed that the construction team should work under the supervision of environment protection departments and PJSSA, and PES should be made with the promises of setting up noise barriers, speed bumps 


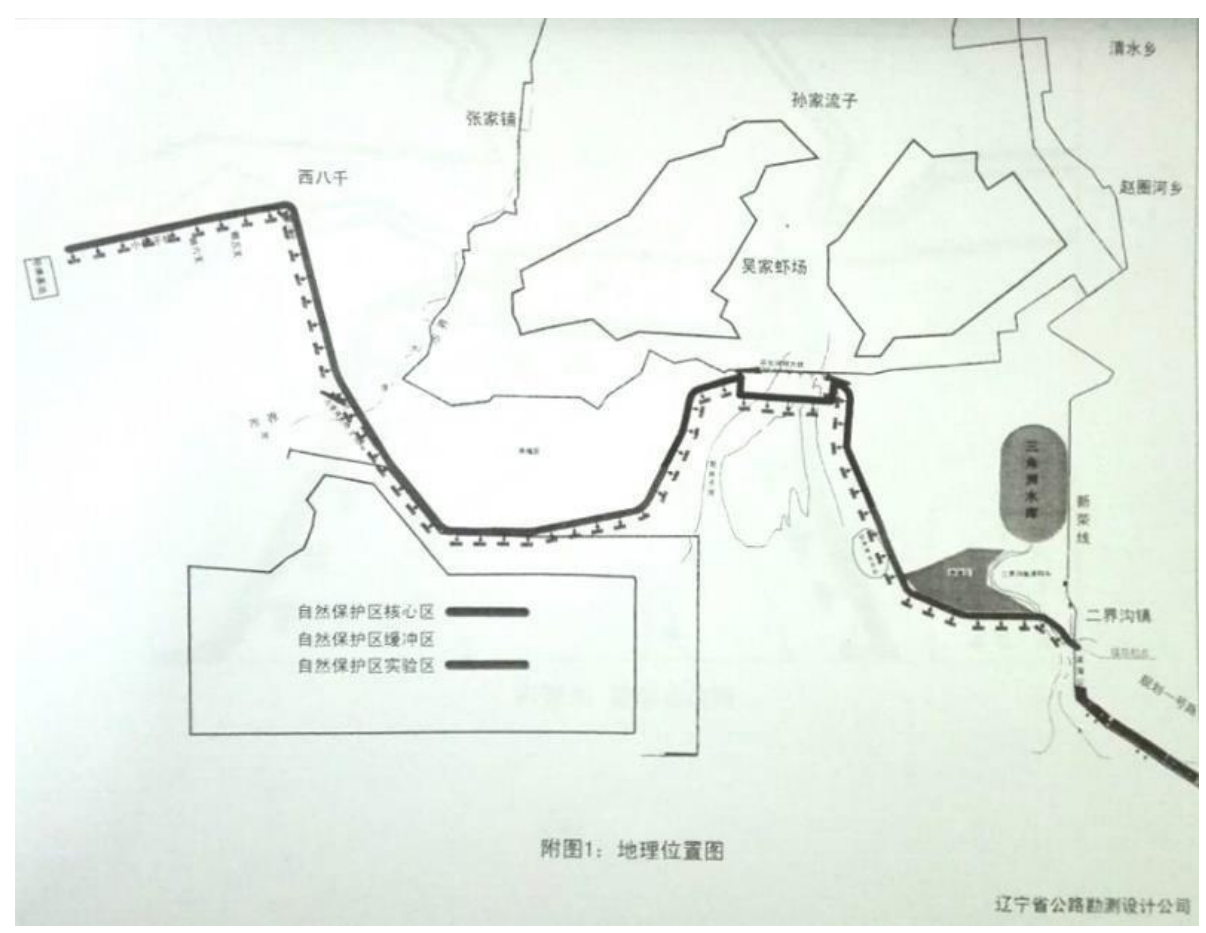

Figure 2. Road design illustration in the final EIA report, provided by Walk with Elephants (NGO). The bold line represents the highway path.

and artificial islands. After the three-month marathon of negotiation, a revised proposal was achieved. The planners adjusted their work accordingly, so that it could be approved in EIA report. In this final proposal, the elevated bridge was $2 \mathrm{~km}$ south of the original plan, which means the spotted seals have to cross the pile foundation of the bridge to reach their former breeding shoals.

In June $13^{\text {th }}$, the "2011 NGOs' Campaign" came to an end. In the newly composed EIA report, route selection changed according to the final proposal. As propaganda asserted, it is a "huge victory" in the perspective of NGO's participation in environmental governance. However, it is obviously not the beginning of spatial government conflicts in this region, and far from the end.

\section{Consequences and impacts of NGOs' participation}

The Construction of Pingyuan water reserve in 1992 expelled the Saunders's Gull from their origin breeding habitat east to the Liaohe River. The state has then investigated over 4.1 million RMB (approx. 0.7 million USD) to establish a $380 \mathrm{hm}^{2}$ species conservation zone southwest to the water reserve. This investigation proved to be futile, as the Saunders's Gull chose Nanxiaohe, west to the Liaohe River as their new breeding ground. When the news about Liaoning Provincial Seaside Highway project first went to public in 2007, Detian Liu,
Chairman of PASG started to negotiate with responsible local officials via informal communication channels. His effort successfully resulted in a revised route selection for Nanxiaohe Section, $4.7 \mathrm{~km}$ north to the original proposal.

This successful case encouraged Tian to advocate his proclaim. However, he was facing a more complex situation. By the end of 2009, the Liaoning Provincial Seaside Highway has finished construction work except for Panjin Section. Pressure was on the local government to organize construction work as soon as possible. By the time Tian noticed the official announcement, deadline for submitting public opinion has already passed. The geographical condition left few possibility for an alternative plan. Though the $2 \mathrm{~km}$-south plan was presented in the revised EIA report issued in June, 2011 (Figure 2), Tian personally contacted with the official from environment protection department and transportation department of Panjin City. He was told that a fourth plan will be made, according to which the elevated bridge will be implemented $6 \mathrm{~km}$ north to the breeding ground of spotted seals, crossing the buffer zone and experimental zone of LNNR. The aim of PJSSA has been partially fulfilled. This time, no propaganda was made during the project information disclosure and EIA public participation procedure. In August, 2012, construction work on the site of the initial plan restarted. Environmentalists' report and photos criticizing the construction project were only retweeted for less than 
2000 times online. PJSSA then converted their working focus to the pollution issues of the Liaohe oil field enterprise. By the end of 2015, the official website still writes that construction work of the Liaoning Provincial Seaside Highway- Panjin Section deceased, as project EIA is rejected.

\section{Opinions from diverse stakeholder groups}

During, and after the "2011 NGO's Campaign", local residents remained silent. In the sparsely distributed settlements within the LNNR, major concerns of the residents are the low salary and poor infrastructure, according to the questionnaire survey. Nearly $50 \%$ of the residents see no impact brought by the governance of LNNR. The others report a decrease of employment by local agriculture and industry (24\%), and increasing price for living material (20\%). None of their concerns are necessarily related with route selection for Liaoning Provincial Seaside Highway project. Situations are similar to the enterprisers. Since their enterprises are the pillar industry of the region, and implemented prior to the establishment of LNNR, current provisions of nature reserve hardly affect their productive activities. In the campaign, they only cared about whether the highway would be constructed or not, rather than the details of route selection. On the other hand, the NGOs are fully concerned with local issues. They presented keen observation, and stimulated public participation by creating propaganda.

As the campaign evolved, the core problem in this nature conservation region is revealed. Inadequate boundary division and spatial governance of the LNNR brought about unnecessary disputes between environment protection groups. PJSSA and the LNNR department both claim that the habitat of their protected subject would be intruded in different route selection proposals. However, LNNR's jurisdiction is protected by relevant laws, while the habitat of the spotted seals is not, making PJSSA's suggestion extremely vulnerable to arguments from both the project initiators and LNNR officials. If the NGOs could be involved as early as in the process of nature reserves range division, would it contribute to a more effective environmental governance?

\section{Hydropower station project in fish conservation zone}

\section{Background}

As referred in the revised Provisions on the Administration of Adjustments to National Nature Reserves, rational adjustment of the ranges and boundaries could be approved. The national rare fish reserve on the upper reaches of the Yangtze River was established to alleviate the ecological impact of the
Three GorgesDam in 2000. This national nature reserve covers the watershed of upper Yangtze River in four adjacent southwestern provinces. In 2005, ranges of the reserve were adjusted, leaving out space for two hydropower stations (Xiangjia Dam in Yunnan Province and Xiluodu in Sichuan Province) along the river. A third hydropower station project, Xiaonanhai Dam in the experimental zone of national reserve was under preparation. The concept of exploiting water power in Xiaonanhai was first referred in Yangtze River Basin Integrated Plan Brief Report (Changjiang Water Resources Commission of the Ministry of Water Resources, 1988), which was approved by the State Council in 1990. Preliminary construction started in the 1990s, but soon suspended because of the shortage of funds. The station was expected to provide 10.2 billion degrees electricity power to Chongqing Municipality annually, approximately $10 \%$ of current annual electricity usage. Chongqing government pushed preliminary work by negotiating corresponding local authorities and signed the working contract with the Three Gorges Project Development Corporation (TGPDC) in 2006. According to academics and environmentalists, the hydropower station would impose fatal threat to Chinese paddlefish (Psephurus gladius), Yangtze sturgeon (Acipenser dabryanus), Chinese high fin banded shark (Myxocyprinus asiaticus) and other 64 protected species in Yangtze River.

\section{NGOs' activities and influence}

Since 2006, NGOs leaded by FON have been closely focused on Xiaonanhai Project and the nature reserve. By 2009, the only obstacle against Xiaonanhai Project was left to be the prohibition of construction work in nature reserve. In fear of a boundary adjustment of nature reserve would lift the last hurdle for Xiaonanhai Project, six national ENGOs sent a joint letter to the Department of Nature and Ecology Conservation, attempting to participate in the 2010 National Nature Reserve Review Meeting. Their request was declined. In November, 2010, FON was confirmed by an official from MEP, that the range of this national rare fish reserve would be changed. Their worries came true. The reserve's range shrank, excluded area exactly overlapped with the construction site for Xiaonanhai Project (Figure 3). One anonymous official from MEP addressed, that the adjustment was made in order to legalize the Xiaonanhai Project (Han, 2011). Lida Weng, former Head of Water Resource Protection Department, Yangtze River Hydrology Committee and Wenxuan Cao, Chairman of the Aquatic Species Research Center, Chinese Academy of Science were two of the Approval Committee members for this fish reserve adjustment proposal. In the interview conducted by China Newsweek (2011), they claimed that a lobby team was sent by Chongqing Municipal 


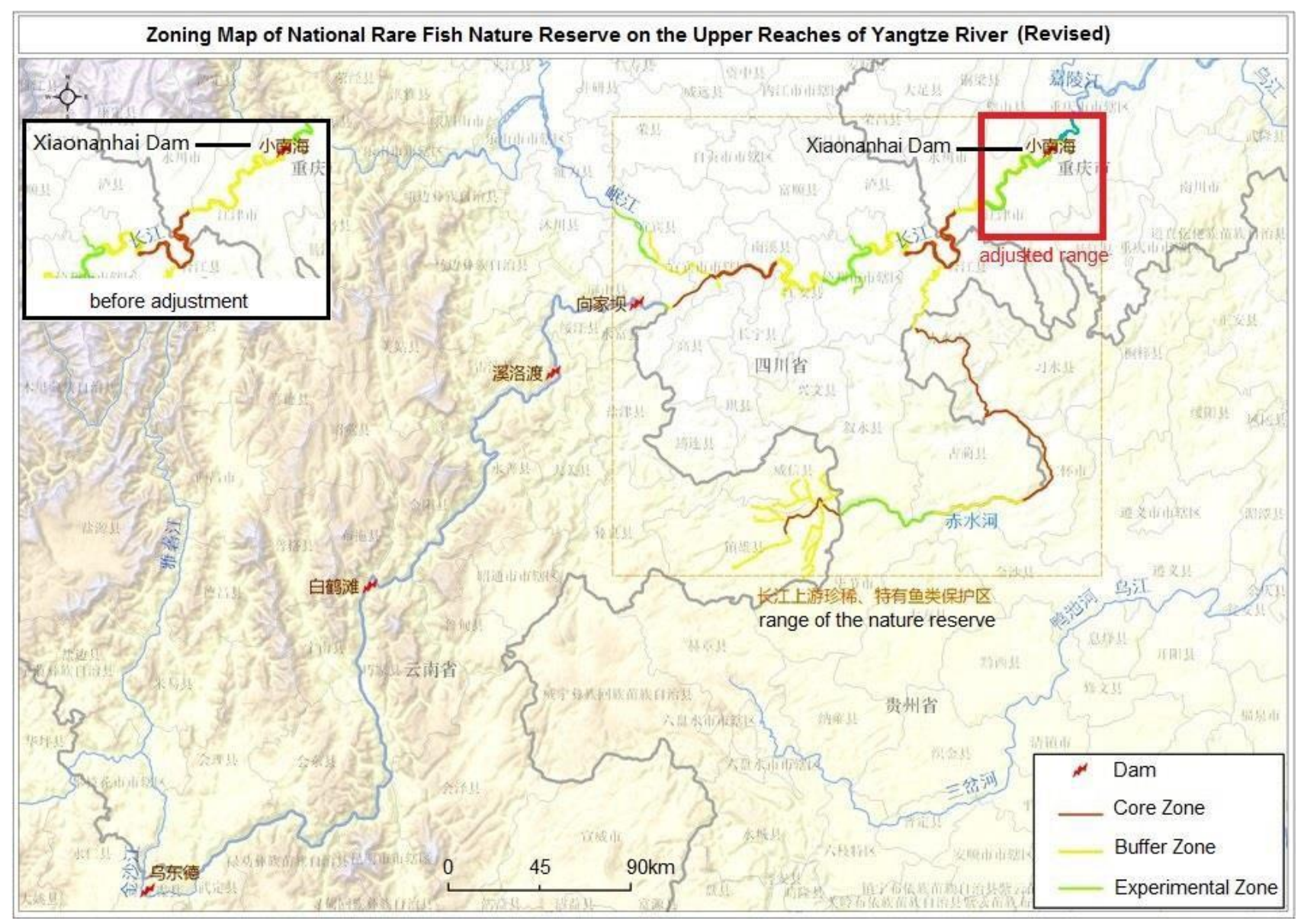

Figure 3. Revised zoning map of the rare fish nature reserve, translated and adapted by author.

Government to "contact with" all reviewers before the review meeting. The adjustment plan then was passed unanimously by the 30 reviewers of the Approval Committee.

FON's application for information disclosure about the range adjustment was responded in February 2011 by MEP, but this effort imposed no direct effect on the nature reserve adjustment proposal. In 2012, the National Development and Reform Commission (NDRC) ratified preliminary construction work for Xiaonanhai Project. The only influential activity of NGOs in this campaign was the propaganda they managed to create. Major approaches to lead propaganda they took were: cooperating with print and web-based media, publishing scientific report (Bo Li et al., 2013), and lobbying concerned government officials. Under this circumstance, both the corresponding governmental authorities and TGPDC were applied enormous pressure by MEP. Though the local government has signed the construction contract with TGPDC in 2006, they were not able to organize a corresponding EIA and get the project started for over nine years. It is unimaginable in China, where preliminary documental work for major hydrological construction project takes averagely two years. In March, 2015, MEP released a prohibition for further construction of Xiaonanhai Project in the approval documents for another TGPDC hydropower station project, Wudongde Dam, since no such document for Xiaonanhai Project has been submitted. This prohibition is regarded as a "sessional victory" of the NGOs, but the "battle" continues. Up to date, there are still contradictory arguments from the local government and several hydrology experts. Academically, they are either completely dismissive about the impact of hydropower station on fish species, or assert that development should not be hindered by several fish's distinction (Zhang, 2015). Having no other effective communication method, NGO leaders' consulted to the web-media. Several of their articles became rhetorically harsh, which resulted in bad public impression. Not only the NGOs are partly paralyzed, as an official from Chongqing Municipal Government interprets, MEP also has no right to interfere with Xiaonanhai Project, since the project was once approved by the State Council. Unless the State Council withdraws the project in a separate document, could there be possibility that the project being abolished once 


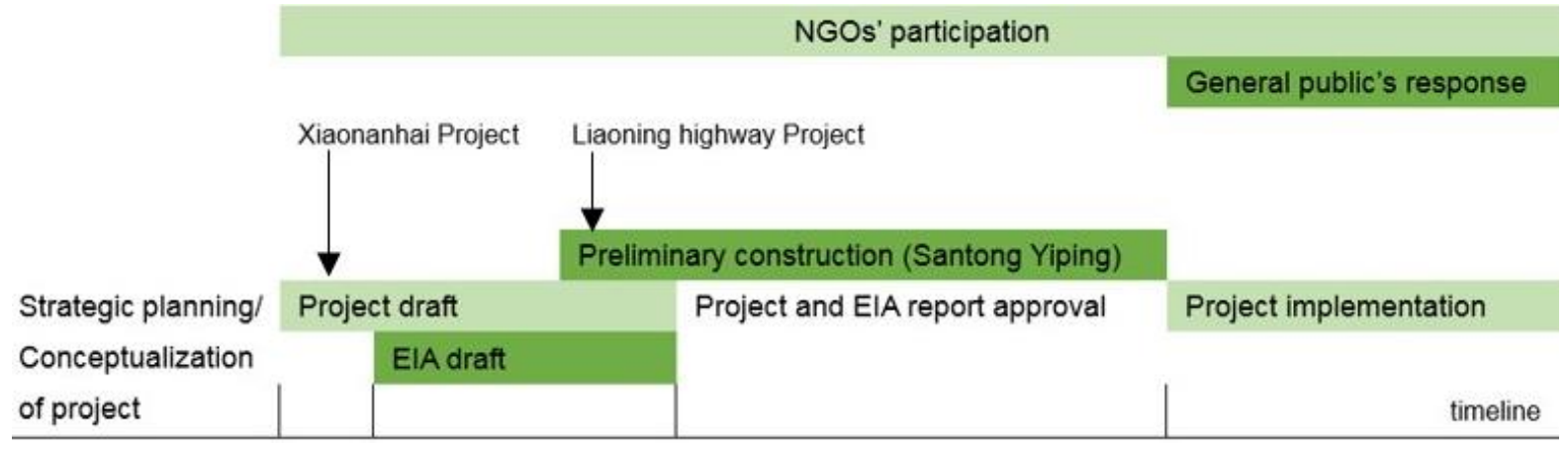

Figure 4. Project development and public intervention timeline.

and for all.

\section{COMPARISON AND CONCLUSION}

In both cases, NGOs were aware of local spatial governance disputes. They identified and took action prior of the general public, before the contentious projects were fully put into practice. As it has been universally acknowledged, NGOs act as inspectors against controversy spatial governance activities. However, the NGOs could identify the problem only when preliminary construction is implemented on site, or project information is disseminated to the public. Their retorts are passively evoked by physical consequences of the project, after the conceptualization of the project is achieved (Figure 4).

In the case of provincial highway project, road design could still be further discussed by various interested groups. An alternative approach, though not in the favor of the officials, is that the highway winds around the range of LNNR, running between Panjin City and the northern boundary of LNNR. Even though there could be much more reluctance for other route selection proposals, the local government is able to accomplish their mandate, providing comprehensive arguments for proposal adjustment. Attention should be drawn to the fact, that variations of route selection would not terminate the entire highway project. As a result, the local government played a relatively less obstructive role in this case, enabling NGOs to perform their work smoothly. Ironically in this case, conflicting groups eventually were two environment protection groups. Route selection proposals advocated by NGOs concentrated only on preventing human invasion in spotted seals habitat, without giving consideration of water fowls habitat in the range of LNNR. Thus NGOs' opinions are meaningful, but as they convey the thoughts from only one interested group, their limitations should not be overlooked.

Though a little delayed in time, the local NGO seized a breakthrough in EIA procedure, the only legitimized participatory working process of a construction project. Their objection to the original route selection proposal has proved to be effective, but there was still a high uncertainty, whether NGO's opinion would be conveyed to the authorities or not. In 2011 NGOs Campaign, the local NGO set up a sound collaboration with other influential NGOs and consulted to the mass media. Their effort won them support from the general public and reversed the attitude of the officials from higher level towards the route selection proposal. When the issue cooled down one year after the campaign, the local government intended to reorganize a route selection proposal and submit to the approval entity as a new project. This time, Tian's report about the unexpected preliminary construction won little media exposure. There might be several reasons, that the media found the issue not newsworthy. One of those is that the new proposal was still in the preparation phase of a corresponding EIA report, so there was no reliable material ground available for NGOs to address their objection. Without the pressure from the general public, no effective attempt was made by NGOs to stop the sporadic constructions on site since then. To conclude, there is a high uncertainty, whether NGO's opinion could be disseminated by influential mass media. When collaboration between NGO and the mass media collapses, the NGOs have extremely limited competence to organize effective activities to make an impact in the decision making process of a project.

Circumstance is different in the NGOs campaign for Xiaonanhai Project. The entire project would be suspended again according to NGOs suggestion. The NGOs took an early action and paid close attention from the preliminary construction work for the project. Expecting to win an advantage by their pre-emptive actions, the NGOs in deed encountered an even more difficult situation. On one hand, the local government held extremely tough stance over this particular project, in order to promote energy development and strengthen their governance performance. On the other hand, since no legitimization for participatory work is promulgated for the project drafting phase, NGOs were not able to establish formal communication with the officials. Their 
attempts were therefore considered ineffective and groundless. Compared with the consequences of the 2011 NGOs Campaign, in which NGOs were involved in the legalized participatory working procedure, no significant improvement could be seen. In both cases, construction project were suspended, and rare species' habitats were temporarily free from human intrusion. It should be noted, however, that in protest of Xiaonanhai Project, conflicts between NGOs and the local government was unusually fierce. Aside from the local government's strong stand concerning the project, prolonged time period of ineffective communication also resulted in the increasing anxiety between NGOs and project advocators. In conclusion, though it is conventionally acknowledged that the NGOs should intervene in a spatial governance project as early as possible, this early intervention strategy proves to be less effective than anticipated, considering the current status of public participation in China.

Instead of formal communication with governmental departments, informal conversation between NGOs and several concerned officials and journalists did make a change. In Xiaonanhai Project, NGOs actively sought to the mass media and intended to lead public opinion. Alongside with each progress made by the local government towards Xiaonanhai Project, numerous news reports sprouted in both print and web-based media. It is still to be discussed by scholars, to what extent a hydropower station project would impact the natural environment, but the mass media helped to convey the concept, that water power project definitely endangers the fish species. Thus the local government was repeatedly negatively labeled by the general public. Consequently, no EIA institution would take the risk to write a positive EIA report for Xiaonanhai Project. It has also be vigorously confirmed in Panjin highway project, that the mass media propel NGOs' participation, regardless of government pressure. Nowadays, the mass media function as a platform for information exchange, and effectively shape public debate by disseminate selected information. The mass media alone is not able to resolve the problem, but plays an important role in jointing concerned individuals and communities, and therefore makes a difference. In the field of conservation governance, NGOs are most likely to be passively involved. By sound cooperation with the media, NGOs could gain support from the general public, and hence achieve a rightful voice against other entities.

\section{SUGGESTIONS AND FURTHER DISCUSSION}

\section{Promote legal environment and clarify governmental responsibilities}

The 2013 promulgated provisions for nature reserve governance are of binding nature. Construction projects would not intrude the range of nature reserve without achieving corresponding approval documents. Yet there is still substantial room for improvement. According to the current legal regime in China, construction projects which have significance in national economic develop strategy are privileged to invade natural conservation area. Definition of "major national project" remains vague, causing misinterpretations among government officials and the general public. Disputes in spatial governance caused by this particular provision prove to be most thorny to resolve. The Committee of Approval for nature reserve range adjustment could be manipulated by powerful officials, which indicates an incomplete implementation of relative provision. Relative provisions must be strictly implemented, to guarantee the purpose of provision fulfilled. On the other side, the environmental departments are relatively disadvantaged, confronting with urgent economic development requisition. The nature reserve governance department should be provided with adequate technic and legislation support, so that they could formulate and cling to a more reasonable nature reserve zoning plan, and hence avoid potential problems.

Various governmental departments collaborate in governing nature reserve in China. However, relevant legislations provide no definitive explanation of each entities' responsibilities. It is difficult for the NGOs to contact with the departments, which are responsible for a certain project. In successful participation cases, all related department were summoned, and each must reaffirm their own stand and liability, so that no department could shirk responsibility. Clearly allocated governance responsibilities would reduce confusion in NGO-government communication. The same reasoning applies in punishment provisions.

\section{Regulate NGOs' performance and strengthen the cooperation of NGOs and the mass media}

The majority of ENGOs in China concentrate on promoting public education about nature protection. They are able to establish a friendly cooperation relationship with the government. However, speaking of spatial governance, the NGOs are most likely to stand opposite to the government. They should carefully choose their approaches to effectively convey their opinion, but at the same time, keep a cooperative attitude. The NGOs are expected to relieve conflicts, not aggravate disputes. They functions as keen supervisor of local governance, while it is still the corresponding governmental departments, who are authorized to conduct governance acts. Last but not least, all NGOs are supervised by the government, they should better regulated their actions to sustain their participation in the long-term.

As had been addressed, the mass media is of vital importance in bridging the ideology gap between general 
public and the officials, and enhancing civil forces. It would be extremely helpful, that the NGOs establish longterm collaborations with the mass media. Once local issues are identified, relevant information could be disseminated as soon as possible, enabling more concerned individuals to contribute their knowledge and wisdom, as well as propel the relevant officials to response. When organizing participatory work, NGOs should also be open to other voices, and hence promote their own proposals. The mass media also reflect the research competent and communication skills of the NGOs. NGOs should endeavor to rationally express their opinions without raising unnecessary disputes.

In China, the NGOs encounter sophisticated challenges to participate in spatial governance. Good news is that the number of successful cases increases in the recent years. There is also an obvious tendency, that the legal infrastructure is advocating information disclosure and public participation in general.

\section{Conflicts of Interests}

The authors have not declared any conflict of interests.

\section{REFERENCES}

Beyer S (2006). Environmental law and policy in the People's Republic of China. Chinese J. Intl. Law 5(1):185-211.

Liu S (2005). Could the general public leads a "EIA reform"? China Youth Daily 2005, Feb. 3.

State Council (1994). The Regulations of the People's Republic of China on Nature Reserves, Decree No. 167 of the State Council.

China Land Administration Bureau (1995). Nature Reserve Land Administrative Measures, Land Administration Law of the People's Republic of China Decree [1995] No. 117.

Standing Committee of the National People's Congress (2002). Law of the People's Republic of China on Appraising of Environment Impacts.

State Council (1996). Decision of the State Council on several issues concerning environmental protection State Council, 2002, Provisions on the Administration of Adjustments to National Nature Reserves

State Council (2013). Provisions on the Administration of Adjustments to National Nature Reserves (Revised).

State Environment Protection Administration (2006). Temporary Act of Environmental Impact Assessment of Public Participation Decree [2006] No. 28.
Schwartz J (2004). Environmental NGOs in China: Roles and Limits, Pacific Affairs 77(1):28-49.

Knup E (1997). Environmental NGOs in China: an overview [J]. China Environment Series. 1(3):9-15.

Beijing NPI NPO Development Center (2010). Report of China Environment NGO Study, 201012 Han, Ziyu, 2011, Razing the last refuge, China dialogue, 20110209.

Li Bo, Yu Yin, Yao Songqiao, Guo Qiaoyu (2013). Last Report of China Rivers, 201312.

Zhang B (2015). Farce of Xiaonanhai hydropower station and the truth behind, Resource, 2015 Vol.5.

Changjiang Water Resources Commission of the Ministry of Water Resources (1988). Yangtze River Basin Integrated Plan Brief Report. 